\title{
The birthday party
}

\author{
Stephen Hancocks OBE \\ Editor-in-Chief
}

The BDJ Upfront section includes editorials, letters, news, book reviews and interviews. Please direct your correspondence to the News Editor,

Adrian O’Dowd at BDJNews@nature.com. Press releases or articles may be edited, and should include a colour photograph if possible.

\section{A} $\mathrm{n}$ old yarn spins the tale of a traveller asking directions to a given destination from a local inhabitant. 'Well,' replies the man 'if I was you and I was heading there, I wouldn't start from here.' For me the story is telling because it succinctly illustrates how someone can wish to be positive and helpful but in actuality completely misses the point.

The National Health Service (NHS) is so well known that it provides one of the few instances where this journal does not generally require its full spelling out in text, the abbreviation NHS being so universally recognised. Reportedly also admired around the world the NHS has been described as close to a religion in the UK because of the ferocity of the loyalty it generates in the population. This year that venerable institution celebrates its $70^{\text {th }}$ birthday which tantalisingly suggests an opportunity to look forward as well as nostalgically ruminating back. However, if, like the advice from the local inhabitant, we are in danger of starting from the wrong place then we need to ask some serious questions, especially in relation to dentistry and to oral health.

The historic details of the state of oral health in 1948 at the inception of the service have been raked over many times but the essentials are still important today. These help us put into context the reasons why we have ended up three-score years and ten later with an awkward and clumsy system no longer fit for the purpose for which the original framework was conceived. After World War II the nation's mouths were in a bad way. Due not so much to the conflict itself but to the decades of previous neglect, poor diet and lack of access to dental care, the population required radical treatment plans of extractions for reasons of both caries and periodontal diseases and the subsequent provision of dentures, primarily full/fulls.
The roadmap included the carrot of piecework which determined and motivated activity to clear as much of the backlog as possible as quickly as possible. Rising to the challenge as, frankly, only dentists could have, we stormed through the early years of the NHS and into the 1960s and 1970s without even raising our heads to look at a horizon on which a perceptibly moving mirage of preventive opportunities was forming.

But, it is very difficult, if not impossible, to try and plan a future of the NHS for dentistry and oral health without being influenced by what we already know of the past. It seems that we are transfixed by a twentieth century obsession to treat while being simultaneously flustered and confused by implementing financial processes that could be adopted to provide effective prevention. There must be
One would reasonably imagine that the currently much quoted statistics on child dental health and the need for so many of our youngsters to have general anaesthetics for tooth extractions would flail the political establishment into a voter-induced frenzy. Nothing. As with sugar and caries, this is entirely overlooked in favour of focussing on the growing national fatball of a congealed mass of diabetes, obesity and cardiac conditions - everything goes in through the mouth yet the powers that be seem determined to place the focus elsewhere. If one pauses for even a moment to contemplate the presence of any true political will to advance dental care, one is struck by the stinging reality of a ringing silence.

At 70 years old, a human might be fit, mentally alert and full of life or fighting

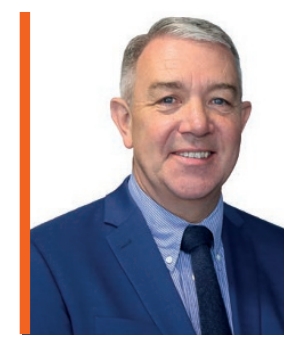

\section{'We are transfixed by an obsession to treat while simultaneously flustered by implementing processes that could provide prevention...'}

an intelligent answer to this but to date it has manifestly failed to materialise.

What does seem clear is that while there is no overtly expressed will by this or any immediately previous governments to proclaim an honest end to NHS dentistry there is, tellingly, no obvious impetus to integrate it into the rest of the NHS. No mentions of any of the recently announced and widely proclaimed $£ 20$ billion of cash being allocated to oral health. No signs at all of any intent to put the mouth back into the body as is often fashionably touted. Indeed, the words that come out of political mouths have no body, no heart and very little, if any, soul - difficult to even find evidence of lip service. dementia, consuming a polypharmacy of drugs and surviving in an old people's home in a state of managed decline. At which extreme is the NHS? Or is it set to bumble along somewhere in the middle; loved and slightly pitied but beyond anyone's conviction to help? In acknowledging the admitted successes of much of the NHS, in relation to oral health we can either slowly blow out the multitude of candles on the birthday cake or take each one and carefully shed light on a new vision. Which will it be? Will we start from where we actually are or forever inactively wish that we were somewhere else? Many happy returns.

DOI: $10.1038 /$ sj.bdj.2018.548 